\title{
Robotik Nefron Koruyucu Cerrahi Yaklaşımında Yeni Gelişmeler ve Sonuçlar
}

\author{
Fatih Hızıı ${ }^{1}$, İsmail Selvi ${ }^{1}$, Okan Baş ${ }^{1}$, Abdullah Erdem Canda ${ }^{2}$, Halil Başar ${ }^{1}$
}

${ }^{1}$ Onkoloji Eğitim ve Araştırma Hastanesi, Üroloji Kliniği, Ankara

${ }^{2}$ Yıldırım Beyazıt Üniversitesi, Tıp Fakültesi, Ankara Atatürk Eğitim ve Araştırma Hastanesi, Üroloji Kliniği, Ankara

\section{Giriş}

$\mathrm{R}$ obotik nefron koruyucu cerrahi; küçük, lokalize renal tümörlerde operasyon zamanını, analjezi gereksinimini, kan kaybını ve iyileşme sürecini azaltmaktadır (1). Renal fonksiyonların korunması ve onkolojik sonuçlar da açık cerrahi yaklaşımla kıyaslanabilir seviyededir (2). Robotik parsiyel nefrektomi (RPN) bu avantajlarından dolayı küçük böbrek tümörlerde giderek artan oranlarda minimal invaziv bir alternatif olarak görülmektedir. Böbrekte çıkartılması zor yerleşimli tümörler, geleneksel olarak hem laparoskopik parsiyel nefrektomi (LPN) açısından hem de RPN açısından deneyimli ellerde dahi rölatif kontrendikasyon olarak görülmektedir (3). Renal hiler tümörlerin, renal damarlara ve üriner toplayıcı sisteme yakınlığından dolayı; parsiyel nefrektomide kısa sıcak iskemi süresi sağlamasında zorluklar mevcuttur. Kompleks renal tümörler, renal vasküler sisteme daha iyi bir ulaşım sağlama, hemostaz için parankimi direk baskılama, daha uzun bir iskemi süresi sağlama açısından genellikle açık yaklaşımla çıkartılır (4). Yine de; multiple retrospektif vaka serileri, RPN'yi yapılabilirlik ve onkolojik sonuçlar açısından açık cerrahiye eşdeğerde görmektedir (5). Robotik renal cerrahideki gelişmelerle bu vakaların minimal invaziv yaklaşımla yapılmasının önünün daha da açılacağ düşünülebilir.

Brandao ve ark.'larının 2014 yilında The Journal of Urology dergisinde yayınlanan "Robot-assisted Partial Nephrectomy for $7 \mathrm{~cm}$ Renal Masses: A Comparative Outcome Analysis" makalesinde (1); $7 \mathrm{~cm}$ ve üzeri renal kitlelerde uyguladıkları RPN deneyimlerini paylaşmak ve bu olgular ile $4 \mathrm{~cm}$ ve altı renal kitlelerde uygulanan RPN'nin cerrahi sonuçlarını kıyaslamayı amaçlamıştır. Cerrahi teknik, renal fonksiyon, onkolojik ve patolojik veriler retrospektif olarak incelenmiştir. Bu çalışmaya 29'u vaka grubu $(7 \mathrm{~cm}$ ve üzeri renal kitleleri içeren) 412'si kontrol grubu $(4 \mathrm{~cm}$ ve altı renal kitleleri içeren) olmak üzere toplamda 441 kişi dahil edilmiştir. Ortalama operasyon süresi 200 dk'ya 180 dk; sıcak iskemi süresi $26.5 \mathrm{dk}^{\prime}$ ya $19 \mathrm{dk}$; tahmini kan kaybı 250 ml'ye $150 \mathrm{ml}$ olarak saptanmış ve sonuçlar kontrol grubunda belirgin olarak daha düşük bulunmuştur. Postoperatif komplikasyonlar \%37.9'a \%15.8 oranı ile vaka grubunda daha yüksek bulunmuştur. Major komplikasyon oranları ise \%18.2'ye \%17 oranı ile her iki grupta benzer bulunmuştur. Postoperatif kan tranfüzyonu ihtiyacı \%24.1'e \% 4.1 oranı ile büyük renal kitlelerde daha fazla bulunurken; pozitif cerrahi sinir \%5.9'a \%3.3 oranı ile gruplar arasinda benzer bulunmuştur. Postoperatif dönemde hesaplanan tahmini glomerüler filtrasyondaki düşme oranlarında \%12.2'ye \%15.8 ile gruplar arasında anlamlı bir farklılık saptanmamıştır. Benzer şekilde, başka yayınlarda da RPN, ekzofitik büyüme paterni olan, polar yerleşimli, histolojisi benign gelme olasılığı olan seçilmiş olgularda, $7 \mathrm{~cm}$ ve üzeri renal kitlelerde, uygun ve güvenilir bir nefron koruyucu cerrahi yaklaşımı sunduğu bildirilmiştir (2-3).

Akca ve ark.'larının yine 2014 yilında The Journal of Urology dergisinde yayınlanan “Robotic Partial Nephrectomy for Cystic Renal Masses: A Comparative Analysis of a Matched-paired Cohort" makelesinde (4) ; kistik ve renal solid neoplastik kitlelere uygulanan RPN sonuçları kıyaslanmıştır. Bu çalışmada Temmuz 2007 ile Temmuz 2013 arasinda 647 olgu incelenmiş ve bunlardan RPN uygulanan 55 kistik kitleli hasta (grup 1) ve 55 solid renal kitleli hasta (grup 2) çalışmaya dahil edilmiştir. Çalışmada renal kitleler bilgisayarlı tomografi (BT) ve magnetik rezonans (MR) ile saptanmiş ve her iki grup yaş, cinsiyet, tümör yükü ve nefrometri skoru açısından kıyaslanmıştır. Grup 1 de RPN sonrası kist rüptürü ve cerrahi sınır pozitifliği saptanmamıştır. Tümörü çevreleyen sağlam renal parankim volümü her iki grupta aynı hesaplanmıştır. Postoperatif dönemde hesaplanan glomerüler filtrasyon oranı $\% 85$ e $\% 86$ olarak hesaplanmış ve gruplar arasında anlamlı bir farklılık bulunmamıştır. Yine iki grup arasında toplam komplikasyonlar açısından farklılık saptanmamıştır. Grup 1'de 30 hastada (\%54.5) grup 2'de ise 47 hastada (\%85.5) patoloji renal hücreli karsinom olarak gelmiştir. Sonuç olarak; RPN yöntemi, şüpheli kistik renal neoplastik kitlelerde, solid kitlelerde olduğu gibi güvenle ve etkili bir biçimde uygulanabildiği bildirilmiştir. Bu sayede karşılaşılan kistik renal kitlelere, uygulanabiliyorsa nefron koruyucu cerrahi önerilmeli ve robotik yaklaşım bu cerrahi için etkili bir alternatif olarak sunulabileceği başka çalışmalarda da bildirilmiştir (5-6).

Desai ve ark.'larının 2014 yılında European Urology'de 
yayınlanan "Robotic Partial Nephrectomy with Superselective Versus Main Artery Clamping: A Retrospective Comparison" isimli makalesi (7) de içerdiği sonuçlar açısından oldukça ilgi çekmektedir. Son dönemlerde parsiyel nefrektomide ana renal arter oklüzyonu yapmayan tekniklere olan ilgi artmaktadır. Bu çalışmada da RPN esnasında ana renal arter yerine süperselektif arter kontrolünün perioperatif sonuçları kıyaslanmıştır. RPN uygulanan 121 hasta retrospektif olarak değerlendirilmiş ve bunlardan 58'i süperselektif grup (Grup 1), 63' ̈̈ ana arter klemplenen grup (Grup 2) olarak ele alınmıştır. Grup 1'de tümöre özgü devaskülarizasyon gözlenmiş, devam eden arteryel perfüzyon kalan böbrek dokusuna yetmiştir. Grup 2'de ise ana renal arter klemplenmiş ve ardından global renal iskemi oluşmuştur. Grup 2 ile karşılaştırıldığında, Grup 1'deki tümörler daha büyük (3.4 cm'ye 2.6 $\mathrm{cm})$ ve daha hiler yerleşimli bulunmuştur (\%24'e \%6). Grup 1 'dekiler daha uzun ortalama operasyon süresine, daha fazla transfüzyon oranlarına (\%4'e \%6) sahip olmakla beraber; her iki grubun tahmini kan kaybı (200 ml'ye $150 \mathrm{ml})$, perioperatif komplikasyonları (\%15'e \%13) ve hastanede kalış süresi benzer saptanmıştır. Grup 1'de hesaplanan glomerüler filtrasyon oranındaki tahmini düşüş takip eden süreçte daha az olarak belirlenmiştir (\%1'e \%17). BT ölçümlerinde, Grup 1'dekilerin daha büyük tümör boyutu ve volümüne (19 ml'ye $8 \mathrm{ml}$ ) sahip olmalarına karşın daha geniş renal parankim korunmasına (\%95'e \%90) sahip oldukları tespit edilmiştir. Sonuç olarak denebilir ki; süperselektif vasküler kontrol ile yapılan RPN, global renal iskemi oluşmaksızın tümör eksizyonunu sağlamaktadır. Kan kaybı, komplikasyonlar, pozitif cerrahi sınır oranları; ana arter klemplenmesi yöntemiyle kıyaslanınca daha düşük veya benzer bulunmuştur. Yöntemin başlangıçtaki gelişimsel sürecinde, kısıtlılıklardan dolayı daha fazla perioperatif transfüzyon ihtiyacı ve daha uzun operasyon süresi gözlenmiştir. Ancak yöntemin daha iyi renal fonksiyon koruması sağladığını kanıtlamak için daha fazla prospektif randomize çalışmaya ihtiyaç olduğu başka çalışmalarda da bildirilmiştir (8-9).

Canda ve Balbay da 2014 yılında Robotic Surgery Research and Reviews dergisinde yayımlanan "Robotic zero ischemia partial nephrectomy: step by step surgical technique with tips and tricks" sıfır iskemi RPN ile ilgili kendi deneyim ve cerrahi tekniklerini anlattıkları yayınlarında, günümüzde birçok renal kitlenin insidental ve küçük boyutlu olarak saptandığını belirterek, robotik cerrahinin sağladığı hızlı ve ince doku diseksiyonu, kolay renal rekonstrüksiyon ve intrakorporeal sütür atılabilmesi, üç boyutlu ve magnifiye görüntü sağlanması, ellerdeki yorulmaya bağlı oluşabilecek titremelerin cerrahi sahaya iletilmesinin önlenmesi ve robotun 3. kolunun da aktif olarak cerrahi sırasında kullanılması sayesinde, özellikle böbrekte periferik yerleşimli ve boyutu 3 $\mathrm{cm}^{\prime}$ den ufak tümörlerde renal arter klemplenmesi yapılmadan, sıcak iskemi ile güvenli ve etkili şekilde RPN yapılabileceğini bildirmişlerdir. Yine bu makalede tümör boyutu 3 cm'den küçük olan kitlelerin patolojik inceleme sonuçlarında renal hücreli karsinom saptanabileceğini de belirtmişlerdir (10).

Kumar ve ark.'larının yine 2014 yılında European Urology'de yayınlanan "Robot-assisted Partial Nephrectomy in Patients with Baseline Chronic Kidney Disease: A Multiinstitutional Propensity Score-Matched Analysis" isimli makalesi (11) de farklı bir bakış açısı ile olaya yaklaşan ilgi çekici başka bir güncel çalışmadır. RPN, kronik böbrek has- talığı (KBH) zemininde renal fonksiyonları korumak için ek değişiklikler sunmaktadır. Bu çalışmada amaçlanan, $\mathrm{KBH}$ olanlarda uygulanan RPN'nin fonksiyonel sonuçları, KBH olmayanlarda uygulanan RPN sonuçları ile görece kıyaslanmıştır. 2007 ile 2012 arasında 1197 hasta bu çalışmaya dahil edilmiştir. Bunlarda 172'si KBH var olan ve tahmini glomerüler filtrasyon oranı $15-60 \mathrm{ml} / \mathrm{dk} / 1.73 \mathrm{~m}^{2}$ olup RPN uygulanan grubu oluşturmuştur. 121 hastanın perioperatif sonuçları $\mathrm{KBH}$ olmayan ve tahmini glomerüler filtrasyon oranı $>60 \mathrm{ml} /$ $\mathrm{dk} / 1.73 \mathrm{~m}^{2}$ kontrol grubu ile kıyaslanmıştır. KBH zeminindeki grupta, postoperatif ilk günlerde glomerüler filtrasyon oranındaki düşüş daha az (-5.1'e -10.9) iken ortalama 12.6 aylık takip sonrasında bu düşüş oranı -2.8'e - 9.1 şeklinde kalmiş ve bu grupta $\mathrm{KBH}$ evrelemesinde ilerleme daha az olarak saptanmıştır (\%11.8'e \%33.1). Bu grubun postoperatif ilk 2 gün içerisinde taburculuk oranları daha düşük bulunmuştur (\%39.7'ye \%56.2) ve cerrahi komplikasyon riskleri \%21.5'e $\% 10.7$ ile daha fazla saptanmıştır. Sonuç olarak; KBH zemininde yapılan RPN sonrası renal fonksiyonlarda göreceli olarak daha az bir düşüş saptansa da cerrahi komplikasyonları $\mathrm{KBH}$ olmayanlara göre daha fazla ve hastanede yatış süresi daha uzun olarak belirlenmiştir (12-13). Yine de çalışmanın ana kısıtlayıcı noktası retrospektif oluşu olduğundan daha başka incelemelere ihtiyaç bulunmaktadır.

Ghani ve ark.'larının 2014 yılında The Journal of Urology dergisinde yayınlanan "Practice Patterns and Outcomes of Open and Minimally Invasive Partial Nephrectomy Since the Introduction of Robotic Partial Nephrectomy: Results from the Nationwide In patient Sample" isimli makalesinde (14); açık ve minimal invaziv parsiyel nefrektomi ile RPN'nin pratik yöntemleri ve perioperatif cerrahi sonuçları kıyaslanmıştır. Ekim 2008 ile Aralık 2010 arasında non-metastatik hastalarda açık, laparoskopik ve robot yardımlı parsiyel nefrektomi uygulanmış ve hangi yöntemin seçileceğini belirlerken yıl, hasta ve hastane özellikleri belirleyici olmuştur. Çalışmada 38.064 vakanın \%66.9'u açık, \%23.9'u robotik ve \%9.2'si laparoskopik yöntemle yapılmıştır. 2010' da göreceli yıllık vaka artışları açık yöntemde \%7.9, robotik yöntemde \%45.4 ve laparoskopide \%6.1 olarak bulunmuştur. Açık metod ile karşılaştırıldığında, minimal invaziv yöntemlerde (robotik ve laparoskopik) daha az kan tranfüzyon ihtiyacl, postoperatif komplikasyon ve hastanede kalış süresi olduğu saptanmıştır. Intraoperatif komplikasyon ise sadece robotik yöntem uygulanan hastalarda daha az olarak görülmüştür. Sonuç olarak görülmüştür ki, RPN'nin uygulamadaki yayılımı hızlı ve güvenilirdir. Açık parsiyel nefrektomi ile kıyaslandığında, RPN pek çok alanda üstünlüğe sahipken, sadece hastanede kalış süresi olarak laparoskopik metodun $R P N^{\prime}$ den daha üstün olduğu görülmüştür. Diğer yayınlarda da yeni yaklaşımların artık RPN'nin yavaş yavaş laparoskopinin yerini alarak en sık kullanılan minimal invaziv parsiyel nefrektomi olma yolunda ilerlediğini göstermektedir (15-16).

Klatte ve ark.'larının yine 2014 yilında The Journal of Urology dergisinde yayınlanan "Systematic Review and Meta-Analysis of Perioperative and Oncologic Outcomes of Laparoscopic Cryoablation Versus Laparoscopic Partial Nephrectomy for the Treatment of Small Renal Tumors" isimli makalesi (17) de ele aldığı sonuçlar açısından okunmaya değerdir. Bu çalışmada küçük renal kitlelerde minimal invaziv tedavi olarak laparoskopik Kriyoablasyon (LK) , minimal invaziv parsiyel nefrektomiye (robotik ve laparoskopik) bir alternatif olarak ele alınmıştır, fakat yöntemin güvenilirliği 
ve onkolojik etkinliği konusunda sınırlı veri bulunmaktadır. Laporoskopik parsiyel nefrektomi (LPN) ve robot yardımlı parsiyel nefrektomi (RPN) ile kıyaslandığında, LK'nin daha kısa operasyon süresine (ortalama $35.45 \mathrm{dk}$ daha kısa), daha az kan kaybına (130.11 ml), daha az hastanede kalış süresine (1.22 gün) ve total, ürolojik ve non-ürolojik komplikasyonlarda daha az risk oranına sahip olduğu gözlenmiştir. Ancak bu metotta hastalarda lokal ve metastatik tümör progresyonu görülmesinde belirgin bir risk artışı mevcuttur. Sonuç olarak denilebilir ki, onkolojik sonuçlar açısından LK'nın daha kötü olduğu kanıtlanmışken, perioperatif sonuçlar açısından LK daha avantajlı olarak görülmektedir. Tüm bu veriler göz önüne alındığında, cerrahi rezeksiyon olguların çoğunda ön planda görülmektedir. Kanser kontrolü ile perioperatif komplikasyon riskleri arasındaki denge düşünüldüğünde, hangi yaklaşımın seçileceği kararının hasta açısından önemi başka çalışmalarda da bildirilmiştir (18-19). Prospektif, randomize, kontrollü çalışmaların uzun dönem sonuçlarına bu açıdan da büyük ihtiyaç bulunmaktadır.

Sonuç olarak kendi klinik bilgilerimize göre de RPN, T2 evreye kadar olan böbrek kitlelerinde açı parsiyel nefrektomi (APN)'ye alternatif bir cerrahidir. RPN'nin uzun dönem onkolojik etkinliğinin literatür verileri ışığında daha da açık bir şekilde ortaya konulması için çalışmaların devamının gerektiği bir gerçektir. Küçük boyutlu böbrek kitlelerinde APN standart tedavi yöntemi olmasına rağmen; RPN, teknik ve deneyimin gelişmesi ile birlikte önem kazanmakta ve standart tedavi olma yolunda hızla ilerlemektedir. Klinik çalışmalarımızla biz de bu konuyu daha geniş bir çalışma grubunda irdelemeyi hedeflemekteyiz.

\section{Kaynaklar}

1. Brandao LF, Zargan $H$, Autorino $R$, et al. Robotassisted Partial Nephrectomyfor $7 \mathrm{~cm}$ Renal Masses: A Comparative Outcome Analysis. J Urol. 2014; 14: 1-7.

2. Karellas ME, O’Brien MF, Jang TL. Partial nephrectomy for selected renal cortical tumours of $7 \mathrm{~cm}$. BJU Int. 2010; 106: 1484-1487.

3. Patel HD, Mullins JK, Allaf ME. Trends in renal surgery: robotic technology is associated with increased use of partial nephrectomy. J Urol. 2013; 189: 1229-1235.

4. Akca O, Zargan H, Autorino R, et al. Robotic Partial Nephrectomy for Cystic Renal Masses: A Comparative Analysis of a Matched-paired Cohort. J Urol. 2014; 84: 93-98.

5. Campbell SC, Novick AC, Belldegrun A, et al. Guideline for management of the clinical T1 renal mass. J Urol. 2009; 182: 1271-1279.

6. Autorino R, Khalifeh A, Laydner H, et al. Robotic partial nephrectomy for completely endophytic renal masses: a single institution experience. BJU Int. 2014; 113: 762-768.

7. Desai MM, Abreu ALC, Leslie S, et al. Robotic Partial Nephrectomy with Superselective Versus Main Artery Clamping: A Retrospective Comparison. European Urology 2014; 5497: 1-7.
8. Thompson RH, Lane BR, Lohose CM, et al. Renal function after partial nephrectomy: effect of warm ischemia relative to quantity and quality of preserved kidney. Urology 2012; 79: 356-60.

9. Campbell SC, Novick AC, Belldegrun A, et al. Guidelines for management of the clinical T1 renal mass. J Urol 2009; 182: 1271-9.

10. Canda AE, Balbay MD. Robotic zero ischemia partial nephrectomy: step by step surgical technique with tips and tricks. Robotic Surgery: Research and Reviews 2014: $1 ; 1-9$.

11. Kumar RH, Sammon JD, Kaczmarek BF, et al. Robotassisted Partial Nephrectomy in Patients with Baseline Chronic Kidney Disease: A Multi-institutional Propensity Score-Matched Analysis. European Urology 2014; 65: 1205-1210.

12. Guillotreau J, Yakoubi R, Long JA, et al. Robotic partial nephrectomy for small renal masses in patients with preexisting chronic kidney disease. Urology 2012; 80: 845-51

13. Kaouk JH, Hillyer SP, Autorino R, et al. 252 robotic partial nephrectomies: evolving renorrhaphy technique and surgical outcomes at a single institution. Urology 2011; 78: 1338-44.

14. Ghani KR, Sukumar S, Sammon JD, et al. Practice Patterns and Outcomes of Open and Minimally Invasive Partial Nephrectomy Since the Introduction of Robotic Partial Nephrectomy: Results from the Nationwide In patient Sample. J Urol. 2014; 191: 907-913.

15. Pinto PA: Renal carcinoma: minimally invasive surgery of the small renal mass. Urol Oncol 2009; 27: 335.

16. Yu HY, Hevelone ND, Lipsitz SR, et al: Use, costs and comparative effectiveness of robotic assisted, laparoscopic and open urological surgery. J Urol 2012; 187: 1392.

17. Klatte T, Shariat SF, Remzi M. Systematic Review and Meta-Analysis of Perioperative and Oncologic Outcomes of Laparoscopic Cryoablation Versus Laparoscopic Partial Nephrectomy for the Treatment of Small Renal Tumors. J Urol 2014; 191:1209-1217.

18. Klatte T, Grubmüller B, Waldert $M$, et al: Laparoscopic cryoablation versus partial nephrectomy for the treatment of small renal masses: systematic review and cumulative analysis of observational studies. EurUrol 2011; 60: 435.

19. Lughezzani G, Cestari A, Buffi NM, et al: Nephron sparing surgery for the treatment of small renal masses: comparison between open partial nephrectomy, laparoscopic partial nephrectomy and laparoscopic cryoablation. Eur Urol Suppl 2009; 8: 126.

Yazışma Adresi:

Fatih Hizlı

Onkoloji Ĕgitim ve Araştırma Hastanesi Üroloji Kliniğgi,

Demetevler, 06530, Ankara

Tel: +90 5324734441

Fax: +903123454979

e-mail: fatihhizli33@yahoo.com 